\title{
A seroepidemiological survey of Mycobacterium avium subsp. paratuberculosis in sheep from North of Portugal ${ }^{1}$
}

\author{
Ana C. Coelho ${ }^{2}$, Maria L. Pinto ${ }^{2}$, Adosinda M. Coelho ${ }^{3}$, Alfredo Aires ${ }^{2}$ \\ and Jorge Rodrigues ${ }^{2}$
}

\begin{abstract}
Coelho A.C., Pinto M.L., Coelho A.M., Aires A. \& Rogrigues J. 2010. A seroepidemiological survey of Mycobacterium avium subsp. paratuberculosis in sheep from the North of Portugal. Pesquisa Veterinária Brasileira 30(11):903-908. Departamento de Ciências Veterinárias, CECAV, Universidade de Trás-os-Montes e Alto Douro, 5001-801 Vila Real Codex, Portugal. E-mail: accoelho@utad.pt

The aim of this study was evaluate the risk factors for Mycobacterium avium subsp. paratuberculosis (Map) seroprevalence in sheep in the North of Portugal. The effects on seroprevalence of several variables such as individual characteristics, management practices, farm characteristics, animal health, and available veterinary services were evaluated. This information was then used in a multivariable logistic regression model in order to identify risk factors for Map seropositivity. Univariable analysis was used to screen the variables used in the logistic regression model. Variables that showed $p$ values of $<0.15$ were retained for the multivariable analysis. Fifteen variables were associated with paratuberculosis in univariable analysis. The multivariable logistic regression model identified a number of variables as risk factors for seropositivity like sheep pure local and/or a cross of a local breed $(\mathrm{OR}=2.02)$, herd size with 31-60 head $(O R=2.14)$, culling during the Spring-Summer season ( $O R=1.69)$ and the use of an anti-parasitic treatment such as Ivermectin as the only anti-parasitic medication $(\mathrm{OR}=5.60)$. Potential risk factors identified in this study support current recommendations for the control of paratuberculosis.
\end{abstract}

INDEX TERMS: Mycobacterium avium subsp. paratuberculosis, sheep, logistic regression, risk factors, Portugal.

RESUMO.- [Rastreio seroepidemiológico de Mycobacterium avium subsp. paratuberculosis em ovinos no Norte de Portugal.] Neste trabalho efectuou-se o estudo dos factores associados à seroprevalência da infecção ovina por Mycobacterium avium subspecies paratuberculosis (Map). Foram investigadas variáveis como as características individuais, práticas de maneio, características da granja, saúde animal e intervenções de sanidade efectuadas no animal. A análise multivariada de regressão logística foi usada para identificar estes factores associados com a seroprevalência da infecção. De acordo com os

\footnotetext{
${ }^{1}$ Received on January 23, 2009.

Accepted for publication on July 21, 2010.

2 Departamento de Ciências Veterinárias, CECAV, Universidade de Trás-os-Montes e Alto Douro, 5001-801 Vila Real Codex, Portugal. *Autor para correspondência: accoelho@utad.pt

${ }^{3}$ Direcção de Serviços Veterinários da Região Norte, Divisão de Intervenção Veterinária de Vila Real, Núcleo do Corgo, 5000-421 Vila Real, Portugal.
}

resultados da análise univariada associaram-se, com o resultado positivo à infecção $(p<0,15), 15$ variáveis. Após a aplicação do modelo de análise multivariada encontraram-se quatro factores de risco com significância estatística: rebanhos de raças autóctones e seus cruzamentos $(\mathrm{OR}=2,02)$; tamanho do efectivo entre 31-60 animais $(\mathrm{OR}=2,14)$; época de abate na Primavera-Verão $(\mathrm{OR}=1,69)$; uso de ivermectina como único antiparasitário $(\mathrm{OR}=5,60)$. Os potenciais factores de risco identificados neste estudo suportam as recomendações currentes para o controlo da paratuberculose.

TERMOS DE INDEXAÇÃO: Mycobacterium avium subsp. paratuberculosis, ovinos, regressão logística, factores de risco, Portugal.

\section{INTRODUCTION}

Paratuberculosis is a chronic infectious disease affecting sheep that is caused by Mycobacterium avium subsp. pa- 
ratuberculosis (Map). The disease is prevalent worldwide and has a significant financial impact on those affected (Losinger 2006).

Many factors can influence the prevalence and spread of paratuberculosis. Several individual and management practices have been identified as potential risk factors for the introduction and spread of the disease (Mainar-Jaime \& Vázquez-Boland 1998, Dieguez et al. 2008). There are other factors that appear to act in preventing seroprevalence (Muskens et al. 2003). Important preventive measures identified through risk analysis included limiting contact between the young stock and the adult herd, and correct hygiene and housing practices - given that faecal contamination of the animals' environment is one of the main ways that the infection is spread (Wells \& Wagner 2000).

There are a number of studies available which evaluate the potential risk factors associated with the transmission of paratuberculosis in cattle (Jakobsen et al. 2000, Daniels et al. 2002, Muskens et al. 2003, Dieguez et al. 2008). However, less is known about the transmission and spread of Mycobacterium avium subsp. paratuberculosis in sheep (Whittington \& Sergeant 2001). Only a small number of studies have been conducted to investigate epidemiological factors in this species (Mainar-Jaime \& Vázquez-Boland 1998, Reviriego et al. 2000, Lugton 2004, Dhand et al. 2005).

In Portugal, risk factors for ovine paratuberculosis have not been previously defined. The evaluation of potential risk factors should contribute vital information towards planning and developing programs to prevent and control ovine paratuberculosis (Kennedy \& Benedictus 2001) in the Trás-os-Montes and Alto Douro region.

The aim of this study is to identify the relationship between seropositivity, paratuberculosis and individual, farm and management variables. Multivariable analysis was used to examine the effects of these factors while simultaneously monitoring the presence of confounders and other factors.

\section{MATERIALS AND METHODS}

\section{Study design}

A cross-sectional study was carried out. Sample size (3900 sheep from 150 flocks) was calculated based on the list of flocks registered in the Trás-os-Montes region. Sample size was calculated using an expected prevalence of $10 \%$ and a confidence interval of $95 \%$ meaning that a total of 150 sheep flocks were randomly selected using the program WinEpiscope 2.0. To simplify the sample collection process, the number of samples per flock was fixed at 26 , and therefore only flocks of 26 head or more were taken into account. This enabled a compromise between cost and estimate accuracy to be achieved. Those sheep flocks sampled were allocated proportionally according to the region's 12 territorial Livestock Farmers Organizations (OPP).

\section{Data collection}

Every flock was visited by the original author and general information about individual characteristics, farm management practices, farm characteristics, animal health and veterinary services were obtained via a questionnaire that was administered to the managers of the farms (available in Portuguese from the authors upon request). During the interview, the questions were read out to the farmer by the interviewer and answers were selected from multiple close questions or otherwise written down, that take along $20 \mathrm{~min}$. To evaluate the design of the questionnaire it was pre-tested with farmers from other areas. All questions were related to variables derived from a literature review of potential risk factors for paratuberculosis in ruminants. The questionnaire included 43 questions, $32(74.4 \%)$ of which were close-ended with two to four choices available. Two were mixed questions. Nine (20.9\%) were open questions with two of them requiring complementary quantitative information. Information collected in the survey was classified into eight sections. Epidemiological data about age, sex, and location was also recorded.

\section{Serological procedure}

The collection, processing of sera samples, as well as the anti- Map antibodies detection by a commercial enzyme-linked immunosorbent assay (ELISA paratuberculosis screening test ${ }^{\circledR}$, Institut Pourquier) were performed as previously described (Coelho et al. 2007).

\section{Statistical analysis}

Statistical analyses were performed using SPSS software version 15. Screening of variables for logistic regression was performed using univariable logistic regression between the dependent and independent variables. For logistic regression purposes, the status of each animal (positive/negative) was used as a dependent variable in order to identify any risk factors associated with the prevalence of the disease. All variables from the questionnaire which showed $p<0.15$ at the $95 \%$ confidence level in the univariable analysis were subsequently introduced into a multivariable model (Hosmer \& Lemeshow $1989)$. For variables that presented strong collinearity $(p \leq 0.05)$, one of the two variables was excluded based on biological relevance following actions based on the recommendations of Dohoo et al. (1996).

Potential risk factors significant at $p<0.15$ in the univariable analyses were then evaluated using stepwise regression to construct a multivariable model (Wald test stepwise $p$-Wald value to enter $<0.15$ ). The logistic model was developed using the stepwise approach. Backward elimination followed by a forward selection for each variable at a time was done, using a likelihood ratio test at each step with 0.05 (two-tailed, alpha = 0.05 ) as significance level for removal or entry. The fit of the models was assessed using the Hosmer and Lemeshow goodness-of-fit test (Hosmer \& Lemeshow 1989). The model was rerun until all remaining variables presented statistically significant values $(p<0.05)$.

The logistic regression coefficients $(\beta)$ and their standard errors (S.E. $\beta$ ) obtained from the chosen model were used to calculate the adjusted odds ratios (OR) and their corresponding $95 \%$ confidence intervals.

\section{RESULTS}

\section{Univariable analysis}

One hundred and forty-four sheep were found to be ELISA seropositive $(3.7 \%$, 95\% confidence interval [CI] 3.1 to 4.3) (Coelho et al. 2007). Fifteen variables were associated $(p<0.15)$ with seropositivity in the univariable 
analysis. All of them were included in the logistic regression model. Table 1 shows the odds ratio and $95 \%$ confidence interval of those potential risk and preventative factors associated with seroprevalence on a factor-by-factor basis. These variables included: "Livestock Farmers Organization", "breed", "herd size", "availability of running water", "origin of replacement animals", "duration of winter housing", "culling rate", "season when culling takes place", "neo-natal mortality problems", "anti-parasitic treatment used", "prior awareness of paratuberculosis", "manure accumulation in area used for newborns", "animals grazing on pasture in the same season manure was spread", "access to manure storage areas", and "season when blood samples are collected".

\section{Multivariable logistic regression analysis}

Table 2 shows the seven variables associated $(p<0.15)$ with the prevalence of antibodies for paratuberculosis that were included in the multivariable analysis. The $\beta$ coefficient, standard error, odds ratios and the $95 \%$ confidence level for the factors are also provided in Table 2. Those factors which remain in the model after adjustment are: "breed", "herd size", "duration of winter housing", "season when culling takes place", "anti-parasitic treatment used", "animals grazing on pasture in the same season manure was spread", and "access to manure storage areas".

Herds of between 31-60 head had a higher risk of being seropositive (OR=2.14, 95\% Cl 1.34 to 3.41 ). The logistic regression model showed that pure local breeds and their crosses had higher odds (OR=2.02, 95\% $\mathrm{Cl} 1.28$ to 3.18 ) of being seropositive to Map compared to foreign breeds of sheep and their respective crosses. The odds $(\mathrm{OR}=1.69,95 \% \mathrm{Cl}$ 0.93 to 3.08 ) for seropositivity were higher for sheep belonging to flocks which were culled in the Spring-Summer season.

The OR for a positive-test result seemed to decrease when the duration of winter housing was less than 3 months (OR=0.32, 95\% Cl 0.18 to 0.55 ).

As far as risk factors are concerned, the adjusted model shows that the main risk factor was the use of ivermectin

Table 1. Factors associated with seroprevalence to Mycobacterium avium subsp. paratuberculosis in univariable analysis $(p<0.15)$ in a serosurvey (September 2003 to May 2004) in the Northeast of Portugal

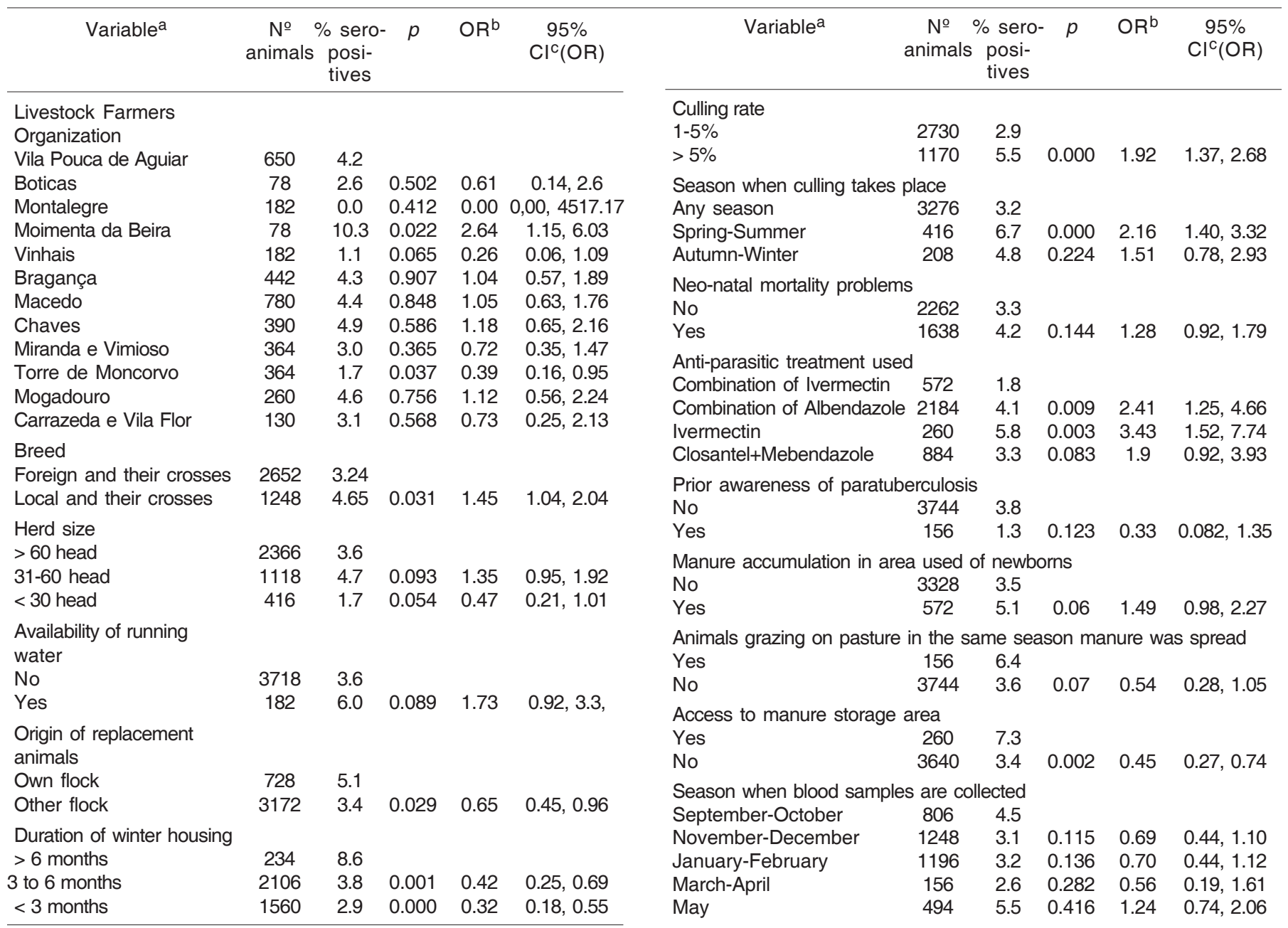

a Variable that were significant $(p<0.15)$ on screening and offered to the logistic model.

b Odds ratio, ${ }^{c}$ Confidence interval. 
Table 2. Results of a multivariable analyses of studied factors in relation to Mycobacterium avium subsp. paratuberculosis seroprevalence in small ruminants flocks in the Northeast of Portugal (September 2003 to May 2004)

\begin{tabular}{|c|c|c|c|c|c|}
\hline Variable & $\beta^{\mathrm{a}}$ & S.E. $\beta^{b}$ & $p$ & $\mathrm{OR}^{\mathrm{c}}$ & $\begin{array}{c}95 \% \mathrm{Cl}^{\mathrm{d}} \\
(\mathrm{OR})\end{array}$ \\
\hline \multicolumn{6}{|l|}{ Breed } \\
\hline Foreign and their crosses & & & & 1.00 & \\
\hline Local and their crosses & 0.73 & 0.23 & 0.002 & 2.02 & $1.28,3.18$ \\
\hline \multicolumn{6}{|l|}{ Herd size } \\
\hline$>60$ head & & & & 1.00 & \\
\hline $31-60$ head & 0.76 & 0.24 & 0.001 & 2.14 & $1.34,3.41$ \\
\hline$<30$ head & -0.70 & 0.44 & 0.108 & 0.50 & $0.21,1.17$ \\
\hline \multicolumn{6}{|l|}{ Duration of winter housing } \\
\hline 3 a 6 months & -1.23 & 0.40 & 0.002 & 0.29 & $0.13,0.64$ \\
\hline$>3$ months & -1.51 & 0.49 & 0.002 & 0.22 & $8.5 \times 10^{-2}, 0.68$ \\
\hline \multicolumn{6}{|c|}{ Season when culling takes place } \\
\hline Any season & & & & 1.00 & \\
\hline Spring-Summer & 0.53 & 0.31 & 0.086 & 1.69 & $0.93,3.08$ \\
\hline Autumm-Winter & $9.6 \times 10^{-2}$ & 0.43 & 0.829 & 1.09 & $0.47,2.54$ \\
\hline \multicolumn{6}{|l|}{ Anti-parasitic treatment used } \\
\hline Combination of Ivermectin & & & & 1.00 & \\
\hline Combination of Albendazole & 1.36 & 0.42 & 0.001 & 3.89 & $1.71,8.89$ \\
\hline Ivermectin & 1.72 & 0.57 & 0.002 & 5.60 & $1.85,16.99$ \\
\hline Closantel+Mebendazole & 1.04 & 0.47 & 0.027 & 2.83 & $1.13,7.09$ \\
\hline \multicolumn{6}{|c|}{ Animals grazing on pasture in the same season manure was spread } \\
\hline Yes & & & & 1.00 & \\
\hline No & -0.89 & 0.49 & 0.067 & 0.41 & $0.16,1.06$ \\
\hline \multicolumn{6}{|c|}{ Access to manure storage area } \\
\hline Yes & & & & 1,00 & \\
\hline No & -0.57 & 0.35 & 0.109 & 0.57 & $0.28,1.13$ \\
\hline
\end{tabular}

as the only anti-parasitic treatment $(\mathrm{OR}=5.60,95 \% \mathrm{Cl} 1.85$ to 16.99). There is also a high relative risk of disease prevalence when the anti-parasitic treatment used was albendazole and its associations (OR=3.89, $95 \% \mathrm{Cl} 1.71$ to 8.89 ), as well as closantel in association with albendazole (OR=2.83, 95\% Cl 1.13 to 7.09 ).

Management practices such as "not spreading manure on pasture to be grazed the same season" (OR=0.41, 95\% $\mathrm{Cl} 0.16$ to 1.06 ), and "preventing ovine access to manure storage areas" (OR=0.57, $95 \% \mathrm{Cl} 0.28$ to 1.13$)$ were considered to be preventative factors.

\section{DISCUSSION}

In this study we report the results of a cross-sectional epidemiological survey conducted in the Portuguese region of Trás-os-Montes e Alto Douro. This is the first epidemiological study performed on small ruminants in the country which aimed to identify those factors associated with paratuberculosis seroprevalence.

From the results of this observational study, a number of important factors have been associated with Mycobacterium avium subsp. paratuberculosis infection in sheep. Risk and preventive factors for Map in cattle had already been the subject of extensive study and discussion (Juste \& Aduriz 1990). However, as far as sheep are concerned the information is sparser and less species-specific (MainarJaime \& Vásquez-Boland 1998, Lugton 2004). Information on the prevalence of paratuberculosis infection is necessary to be able to define measures for its control and prevention (Aduriz et al. 2000).

A number of important factors linked to paratuberculosis in other studies, such as the origin of replacement animals, culling rate and accumulation of manure (Goodger et al. 1996, Mainar-Jaime \& Vázquez-Boland 1998) were only associated with seroprevalence in the univariable analysis.

Results from the logistic regression model used to evaluate risk factors link seropositivity to Map in local breeds and their crosses. Nevertheless, other authors have reported that seroprevalence was higher in foreign breeds and their crosses (Jakobsen et al. 2000, Mainar-Jaime \& VásquezBoland 1998). This observation, taken from the present study, could be explained by the presence of genetic differences responsible for either susceptibility or resistance to infection between breeds (Koets et al. 2000). Another possible explanation could be down to differing management practices between ovine breeds (Chiodini et al. 1984), since foreign-purchased animals are usually managed with more care, therefore reducing the spread of infection. As such, this cannot be said to be a true breed predisposition. It is more likely related to another breed-associated risk factor that was not possible to measure.

The present study indicates higher levels of Map seroprevalence among herd sizes of between 31-60 head than in smaller or larger herds. These findings are in contrast to those observed by Mainar-Jaime \& VázquezBoland (1998), who reported that seropositivity was higher in larger flocks of more than 200 head. These flocks were usually associated with mass management practices which are typically more difficult to control and allow for closer contact between animals and their environment. The reasons behind our results might be that smaller flocks are usually found on private farms. These farms are often found to favour traditional animal management procedures that can favour transmission of infection. However, this also applies to smaller flocks with less than 30 sheep. On the other hand, on large farms, infection is often prevented by the widespread use of measures which promote hygiene, such as organized feeding and cleaning. These findings could also be due to the limited farm space that is a characteristic of most flocks in Trás-os-Montes e Alto Douro, where farmers tend to use practically the same size living area for all flocks with 60 head of sheep or less. The stocking density is subsequently higher and allows greater contact between flocks. This creates a higher bacterial load in the environment and hence the chances of disease transmission will be increased (Muskens et al. 2003). However, this is not problematic in flocks with less than 31 animals. When the size of the flock increases, it becomes necessary to increase the 
size of the farm which in turn brings down the stocking density. In all probability, the results are related to other farming factors not identified in this study.

Another interesting result of our study is that there was a greater association with seropositivity when culling was carried out in the Spring-Summer period. The season when sheep parturition is carried out also overlaps the SpringSummer period. Although it is difficult to be certain, the rise in antibodies associated with parturition may account for our findings (Nielsen et al. 2002, Kudahl et al. 2004), as this season is also closely intertwined with those months associated with sheep delivery and abortion (Kostoulas et al. 2006). These results could also be put down to cold winter conditions, poorer quality pastures, loss of fleece protection that may cause additional stress, and clinical diseases during Spring-Summer (Lugton 2004).

One of the clearest predictors of paratuberculosis seroprevalence in this study was the use of ivermectin as the only anti-parasitic treatment. Ivermectin is a widely used macrocyclic lactone which acts against a wide variety of nematode and arthropod parasites. It is used for the treatment and control of parasites in cattle, horses, and sheep (Geary 2005). The strong association between the use of ivermectin and a higher seroprevalence of paratuberculosis has not been previously reported. This association remained very strong even after controlling for potentially confounding variables in multivariable analysis. Lugton (2004) suggests that factors associated with the control of gastrointestinal parasites do not influence the disease. The reasons for this are unclear, but may be related to the fact that ivermectin's anti-parasitic spectrum fails to include all types of parasites, or to an increase in antiparasitic resistance (Swan et al. 1994, Sangster \& Gill 1999, Köhler 2001). This would increase the probability of sheep enduring increased exposure to parasitic infections, which could cause a sheep's body condition to deteriorate further than other animals and contribute to a higher seropositivity. In this study, albendazole and its associations, as well as combinations of closantel and mebendazole anti-parasitic treatments, increased the prevalence of seropositivity. The reasons may be the same as those applying to ivermectin (Sangster \& Gill 1999, Köhler 2001). Therefore, future studies should evaluate the influence of anti-parasitic treatments on seroprevalence.

Another interesting result of our study was that sheep whose winter housing period lasted less than 6 months were less likely to be seropositive. This is in contrast with the study published by Çetinkaya et al. (1997), in which this variable did not appear to be an important factor for seropositivity. There are several reasons which could explain the differences between the studies, such as climatic differences between Portugal and England, and the species studied (ovine and cattle). It is most likely that the preventative factors unearthed in the present study are related to the prolonged and close contact between sheep which are kept in winter housing for longer than 6 months, which increases the chance of the disease being transmitted to susceptible animals.
In our study, not spreading manure on pasture which is to be grazed in the same season was a preventative factor. This is perhaps to be expected, given that the practice of spreading manure on pasture to be grazed in the same season is a management factor that has been associated with infection in previous studies (Thoen \& Baum 1988, Raizman et al. 2005). This is because when grazing takes place in the same season there is no time for reduction in viable pathogen number. Machackova et al. (2004) recovered the Map from contaminated hay after 4 months on pasture.

One of the most important preventive factors for paratuberculosis was the prevention of access to manure storage areas. This discovery reinforces and extends the reports of several authors concerning sanitary strategies which benefit the flock. Limiting the exposure of animals to contaminated manure is an important measure, since Map is transmitted horizontally with the spread of manure (Daniels et al. 2002). Raizman et al. (2005) identified the practice of spreading manure on crop fields and pastures as an important factor in the transmission of Map among dairy cattle, deer and rabbits.

Due to the limitations imposed by the design of our study (cross-sectional), the results need to be interpreted carefully, given that it was not possible to clearly identify a causeand-effect relationship (Thrusfield 1995). Nevertheless, information from this study could make an important contribution towards future appropriately designed strategies to prevent paratuberculosis infection in the region. Our questionnaire was created to try and measure only individual and global practices previously thought to affect Map transmission. Other factors that may be associated with seroprevalence need to be assessed in future studies.

The results suggest that animal management practices and housing might affect seroprevalence. We found a number of associations between seropositivity and the various factors studied in the questionnaire. To enable a reduction of seroprevalence found in the area, the risk and preventative factors we identified should be taken into consideration. Considering the paucity of epidemiological reports on paratuberculosis in the Trás-os-Montes e Alto Douro region and the absence of any data concerning factors related to either the prevention or the spread of the disease, our results could make a useful contribution towards the prevention of ovine paratuberculosis in the area.

Acknowledgments.- The authors thank the assistance of the owners of the participating sheep flocks, the technicians and colleagues working at the Livestock Farmers Organizations, the staff of the Laboratory of Microbiology of the University of Trás-os-Montes and Alto Douro (Portugal), and to Dr. Ramon Juste, the staff of the Department of Animal Health from the Instituto Vasco de Investigación y Desarrollo Agrario (Spain).

\section{REFERENCES}

Aduriz G., Juste R.A., Garrido J.M. \& Geijo M.V. 2000. Epidemiología y control de la paratuberculosis bovina. Bovis 93:63-73.

Çetinkaya B., Erdogan H.M. \& Morgan K.L. 1997. Relationships between the presence of Johne's disease and farm and management factors in dairy cattle in England. Prev. Vet. Med. 32(3/4):253-266. 
Chiodini R.J., Van Kruiningen H.J. \& Merkal R.S. 1984. Ruminant paratuberculosis (Johne's disease): The current status and future prospects. Cornell Vet. J. 74(3):218-262.

Coelho A.C., Pinto M.L., Silva S., Coelho A.M., Rodrigues J. \& Juste R. 2007. Seroprevalence of ovine paratuberculosis infection in the Northeast of Portugal. Small Rumin. Res. 71(1/3):298-303.

Daniels M.J., Hutchings M.R., Allcroft D.J., Mckendrick I.J. \& Greig A. 2002. Risk factors for Johne's disease in Scotland: The results of a survey of farmers. Vet. Rec. 150:135-139.

Dhand N.K., Eppleston J., Whittington R.J. \& Toribio J. 2005. Risk factors for OJD prevalence in infected flocks. Proc. MLA OJD Harvest Year Conference. Meat and Livestock Australia Limited, Sidney, p.144-151.

Dieguez F.J., Arnaiz I., Sanjuán M.L., Vilar M.J. \& Yus E. 2008. Management practices associated with Mycobacterium avium subspecies paratuberculosis infection and the effects of the infection on dairy herds Vet. Rec. 162:614-617.

Dohoo I.R., Ducrot C., Fourichon C., Donald A. \& Hurnik D. 1996. An overview of techniques for dealing with large numbers of independent variables in epidemiologic studies. Prev. Vet. Med. 29(3):221-239.

Geary T.G. 2005. Ivermectin 20 years on: Maturation of a wonder drug. Trends Parasitol. 21(11):530-532

Goodger W.J., Collins M.T., Nordlund K.V., Eisele C., Pelletier J., Thomas C.B. \& Sockett D.C. 1996. Epidemiologic study of on-farm management practices associated with prevalence of Mycobacterium paratuberculosis infections in dairy cattle. J. Am. Vet. Med. Assoc. 208:1877-1881.

Hosmer D.W. \& Lemeshow S. 1989. Applied Logistic Regression. John Wiley and Sons, New York, NY.

Jakobsen M.B., Alban L. \& Nielsen S.S. 2000. A cross-sectional study of paratuberculosis in 1155 Danish dairy cows. Prev. Vet Med. 46(1):15-27.

Juste R.A. \& Aduriz J.J. 1990. Aspectos epidemiologicos. Ovis 7:6575.

Kennedy D.J. \& Benedictus G. 2001. Control of Mycobacterium avium subsp. paratuberculosis in agricultural species. Revue Scientifique et Technique de L'Office International des Epizooties 20:151-179.

Koets A.P., Adugna G., Janss L.L., Van Weering H.J., Kalis C.H., Wentik G.H., Rutten V.P. \& Schukken Y.H. 2000. Genetic variation of susceptibility to Mycobacterium avium subsp. paratuberculosis infection in dairy cattle. J. Dairy Sci. 83(11):2702-2708.

Köhler P. 2001. The biochemical basis of anthelmintic action and resistance. Int. J. Parasitol. 31(4):336-345.

Kostoulas P., Leontides L., Billinis C., Amiridis G.S. \& Florou M. 2006. The association of sub-clinical paratuberculosis with the fertility of Greek dairy ewes and goats varies with parity. Prev. Vet. Med. 74(2/ 3):226-238
Kudahl A., Nielsen S.S. \& Sorensen J.T. 2004. Relationship between antibodies against Mycobacterium avium subsp. paratuberculosis in milk and shape of lactation curves. Prev. Vet. Med. 62(2):119-134.

Losinger W.C. 2006. Economic impacts of reduced milk production associated with epidemiological risk factors for Johne's disease on dairy operations in the USA. J. Dairy Res. 73(1):33-43.

Lugton I.W. 2004. Cross-sectional study of risk factors for the clinical expression of ovine Johne's disease on New South Wales farms. Aust. Vet. J. 82(6):355-365.

Machackova M., Svastova P., Lamka J., Parmova I., Liska V., Smolik J., Fischer O.A. \& Pavlik I. 2004. Paratuberculosis in farmed and free-living wild ruminants in the Czech Republic (1999-2001). Vet. Microbiol. 101(44):225-234.

Mainar-jaime R.C. \& Vázquez-Boland J.A. 1998. Factors associated with seroprevalence to Mycobacterium paratuberculosis smallruminants farms in the Madrid regions (Spain). Prev. Vet. Med. 34(4):317-327.

Muskens J., Elbers A.R., Van Weering H.J. \& Noordhuizen P.T. 2003. Herd management practices associated with paratuberculosis seroprevalence in Dutch dairy herds. J. Vet. Med. B 50(8):372-377.

Nielsen S.S., Gröhn Y.T. \& Enevoldsen C. 2002. Variation of the milk antibody response to paratuberculosis in naturally infected dairy cows. J. Dairy Sci. 85:2795-2802.

Raizman E.A., Wells S.J., Jordan P.A., Delgiudice G.D. \& Bey R.R. 2005. Mycobacterium avium subsp. paratuberculosis from freeranging deer and rabbits surrounding Minnesota dairy herds. Can. J. Vet. Res. 69(2):32-38.

Reviriego F.J., Moreno M.A. \& Domínguez L. 2000. Soil type as a putative risk factor of ovine and caprine paratuberculosis seropositivity in Spain. Prev. Vet. Med. 43(1):43-51.

Sangster N.C. \& Gill J. 1999. Pharmacology of Anthelmintic resistance. Parasitol. Today 15(4):141-146.

Swan N., Gardner J.J., Besier R.B. \& Wroth R. 1994. A field case of ivermectin resistance in Ostertagia of sheep. Aust. Vet. J. 71:302303.

Thoen C.O. \& Baum K.H. 1988. Current knowledge on paratuberculosis. J. Am. Vet. Med. Ass. 192:1609-1611.

Thrusfield M. 1995. Veterinary Epidemiology. $2^{\text {nd }}$ ed. Blackwell Science, Oxford. 483p.

Wells S.J. \& Wagner B.A. 2000. Herd-level risk factors for infection with Mycobacterium paratuberculosis in US dairies and association between familiarity of the herd manager with the disease or prior diagnosis of the disease in that herd and use of preventive measures. J. Am. Vet. Med. Assoc. 216:1450-1457.

Whittington R.J. \& Sergeant E.S. 2001. Progress towards understanding the spread, detection and control of Mycobacterium avium subsp. paratuberculosis in animal populations. Aust. Vet. J. 79(4):267-278. 